\title{
Catalejo de la Conciliación Judicial ${ }^{1}$
}

\author{
Spyglass of judicial conciliation
}

Luneta de conciliação judicial

Conciliation judiciaire, vue agrandie

\section{Niurka Fournier Duharte ${ }^{2}$ Universidad de Oriente, Cuba}

Revista Derechos en Acción

Año 3/Nº 9 Primavera 2018, 167-194

DOI: https://doi.org/10.24215/25251678e218

ORCID: https://orcid.org/0000-0001-9708-6573

Recibido: 17/11/2018

Aprobado: 01/12/2018

Resumen: La contradicción y el conflicto son categorías filosóficas que el Derecho Procesal, acoge como fundamentos para solucionar las demandas promovidas ante el órgano de la administración de justicia. Es pues, el que coloca la contradicción dentro de la administración de justicia, al convertirlo en litigio, por la acción dinámica de las pretensiones contrapuestas de las partes y los actos procesales del tribunal, hasta resolverlo mediante una sentencia. No obstante, llegado al grado que el litigio adquiera un clímax de estancamiento, las partes, al tomar conciencia del estado en que se encuentra y tener una percepción clara de lo que se quiere o no lograr, en cualquier momento, tratarán de intentar la posibilidad de disipar la contienda, con el fin de lograr un resultado satisfactorio, encargando la solución a terceras personas, por decisión de un

\footnotetext{
1 El artículo forma parte de la Tesis en opción al grado científico de Doctora en Ciencias Jurídicas, que defendiera la autora en el año 2013, titulada: La conciliación judicial en el procedimiento económico cubano", y con el cual obtuviera premio en el Concurso Nacional de la Sociedad Científica de Derecho Procesal de la Unión Nacional de Juristas en el propio año.

2 Jueza profesional Titular de la sala de lo Económico del Tribunal Provincial Popular de Santiago de Cuba con 32 años de labor profesional. Vicepresidenta de la Sociedad Científica de Derecho Económico y Financiero de la Unión Nacional de Juristas de Cuba y Profesora Auxiliar a Tiempo Parcial de la Facultad de Derecho de la Universidad de Oriente
} 
Tribunal juzgador o el uso de métodos alternativos de solución de conflictos; la conciliación judicial es una alternativa para esta finalidad. Motiva la investigación, el análisis de la concepción teórica del tratamiento de la conciliación judicial, deteniendo el estudio en su naturaleza jurídica, formas de manifestación; la coexistencia de la autocomposición y hetero composición, las ventajas y riesgos que asumen el tribunal y las partes al momento de su cumplimiento; hasta enrumbar la armonización de los intereses conflictuales, mediante la correcta aplicación de los principios generales del Derecho.

Palabras clave: Derecho procesal; administración de justicia; conciliación judicial.

Abstract: Contradiction and conflict are philosophical categories that the Procedural Law accepts as foundations to solve the demands promoted before the organ of the administration of justice. It is the one that places the contradiction within the administration of justice, turning it into litigation, by the dynamic action of the opposing claims of the parties and the procedural acts of the court, until it is resolved by means of a sentence. Nevertheless, when the litigation reaches a climax of stagnation, the parties, upon becoming aware of the state in which it is and having a clear perception of what they want or do not achieve, at any time, will try to try the possibility of dissipating the dispute, in order to achieve a satisfactory result, entrusting the solution to third parties, by decision of a court of law or the use of alternative methods of conflict resolution; judicial conciliation is an alternative for this purpose. It motivates the investigation, the analysis of the theoretical conception of the treatment of the judicial conciliation, stopping the study in its legal nature, forms of manifestation; the coexistence of the autocomposition and hetero composition, the advantages and risks that assume the court and the parts at the moment of its fulfillment; until the harmonization of the conflicting interests begins, by means of the correct application of the general principles of the Law.

Keywords: Procedural law; administration of justice; judicial conciliation.

Resumo: A contradição e o conflito são categorias filosóficas que o Direito Processual acolhe como fundamentos para solucionar as demandas promovidas ante o órgão da administração da justiça. É, portanto, que coloca a contradição dentro da administração da justiça, transformando-0 
em processos, pela ação dinâmica das reivindicações conflitantes das partes e do processo no tribunal, para resolvê-lo por meio de uma frase. No entanto, cheguei ao ponto em que a disputa adquirir um clímax de estagnação, as partes que estar ciente do estado que é e ter uma percepção clara do que é desejado ou não alcançado a qualquer momento, eles tentam tentar a possibilidade dissipar o concurso, a fim de alcançar um resultado satisfatório, cobrando a solução para outro, por decisão de um tribunal de julgamento ou o uso de métodos alternativos de resolução de conflitos; A conciliação judicial é uma alternativa para esse fim. Motiva a investigação, a análise da concepção teórica do tratamento da conciliação judicial, interrompendo o estudo em sua natureza jurídica, formas de manifestação; a coexistência de auto-composição e hetero composição, as vantagens e riscos assumidos pelo tribunal e pelas partes no momento do cumprimento; até a harmonização de interesses conflitantes, através da correta aplicação dos princípios gerais do direito.

Palavras-chave: direito processual; administração da justiça; conciliação judicial

Résumé: La contradiction et le conflit sont des catégories philosophiques que le droit procédural reçoit comme base pour résoudre les revendications formulées devant l'organe d'administration de la justice. C'est donc celui qui place la contradiction au sein de l'administration de la justice, en la transformant en litige, par l'action dynamique des demandes opposées des parties et des actes de procédure du tribunal, jusqu'à ce qu'elle soit résolue par un jugement. Toutefois, si le litige atteint un point culminant de stagnation, les parties, conscientes de l'état dans lequel elles se trouvent et ont une perception claire de ce qu'elles veulent ou ne veulent pas réaliser, tenteront à tout moment de dissiper le concours. Afin de parvenir à un résultat satisfaisant en confiant la solution à des tiers, par décision d'un tribunal compétent ou par le recours à d'autres méthodes de résolution des conflits. La conciliation judiciaire est une alternative à cet effet.Motive l'investigation, I'analyse de la conception théorique du traitement de la conciliation judiciaire, en se concentrant dans l'étude de sa nature juridique, les formes de manifestation. La coexistence de l'autocomposition et de l'hétérocomposition est également analysée, ainsi que les avantages et les risques assumés par le tribunal et les parties lors de son exécution, 
jusqu'à ce que celle-ci oriente l'harmonisation des intérêts en conflit, par l'application correcte des principes généraux du droit.

Mot-clés: Droit procédural; administration de la justice; conciliation judiciaire

\section{Notas iníciales}

La contradicción y el conflicto son categorías filosóficas que el Derecho Procesal, acoge como fundamentos para solucionar las demandas promovidas ante el órgano de la administración de justicia. Es pues, el que coloca la contradicción dentro de la administración de justicia, al convertirlo en litigio, por la acción dinámica de las pretensiones contrapuestas de las partes y los actos procesales del tribunal, hasta resolverlo mediante una sentencia.

No obstante, llegado al grado que el litigio adquiera un clímax de estancamiento, las partes, al tomar conciencia del estado en que se encuentra y tener una percepción clara de lo que se quiere o no lograr, en cualquier momento, tratarán de intentar la posibilidad de disipar la contienda, con el fin de lograr un resultado satisfactorio, encargando la solución a terceras personas, por decisión de un Tribunal juzgador o el uso de métodos alternativos de solución de conflictos; la conciliación judicial es una alternativa para esta finalidad.

Motiva la investigación, el análisis de la concepción teórica del tratamiento de la conciliación judicial, deteniendo el estudio en su naturaleza jurídica, formas de manifestación; la coexistencia de la autocomposición y hetero composición, las ventajas y riesgos que asumen el tribunal y las partes al momento de su cumplimiento; hasta enrumbar la armonización de los intereses conflictuales, mediante la correcta aplicación de los principios generales del Derecho. 


\section{De la conciliación judicial: definición, naturaleza jurídica y su manifestación dentro de los estados procesales}

Aunque no es distinguido por la historiografía jurídica la regulación de la conciliación judicial, es oportuno tomar como referente de sus expresiones normativas más tempranas al Código de Ur- Namur, (2050 antes de Cristo), el cual contuvo normas de carácter adjetivas relativas a la conciliación, ${ }^{3}$ al Codex Visigotorum, Libro de los Jueces o Fuero Juzgo ${ }^{4}$ al consagrar el principio de que las partes no podían arreglarse luego que el pleito estaba a cargo del juez. Después de Nuestra Era se recuerda, la Ley de las XII Tablas, contentiva de normas de Derecho Procesal que instaban a concordar, antes de que se determinara la causa o el juicio ${ }^{5}$ y en el orden religioso el Nuevo Testamento, lo aconsejó. ${ }^{6}$

Siglos después, las Ordenanzas de Bilbao, tuvieron implícita la expresión jurídica de la conciliación al prohibirse la admisión de toda demanda por escrito, sin que ante todas las cosas el pretor y cónsules hiciesen parecer ante sí a las partes y procurasen atajar entre ellas el pleito, si buenamente pudiesen ser habidas. ${ }^{7}$

Entre los dos Guerras Mundiales acontecidas en la primera mitad del siglo XX, la generalidad de las disputas conocidas por

3 Vid. LARA PEINADO y LARA GONZÁLEZ: "Los primeros Códigos de la Humanidad", Ed. Tecnos, 2001,p. 127.

4 Esta fue una obra de Eurico y otros reyes visigodos aprobada por el VII Concilio de Toledo a la caída del imperio Romano, existe contradicción en el año de promulgación (entre los años 654 y 646).

5 La Ley de las XII Tablas expresa: " (...)7. En los términos en que se hizo la transacción por el camino, valga.8. Si no transigiesen, determínese la causa antes del medio día en el comisio 0 en el foro, oyendo a los litigantes. 9. Después de mediodía en el comisio o en el foro, sede la acción al que esté presente ".

6 Vid. La Santa Biblia. Antiguo y Nuevo Testamentos, Ed. Sociedades Bíblicas Unidas, España, pp.879-885.

7 Ordenanzas de Bilbao. Apud. MANRESA y NAVARRO, José María y MIGUEL Ignacio: "Ley de Enjuiciamiento Civil Española del 13 de Mayo de 1856. Comentada y explicada", Ed. Legislación y Jurisprudencia, t.1, p.540-558. 
la Corte Internacional fueron resueltas por la conciliación ${ }^{8}$ y la Declaración Universal de los Derechos Humanos de la Organización de Naciones Unidas tuvo como primer principio que, todos los seres humanos deben comportarse fraternalmente los unos con los otros.

La regulación jurídica de la conciliación fue extendiéndose por todos los países y tomó mayor fuerza en la segunda mitad del siglo XX, ante el vertiginoso desarrollo de la industria a nivel mundial y de las relaciones económicas y mercantiles que coexisten cada vez más en el mundo contemporáneo, modificando la forma habitual asumidas por los gremios de comerciantes para la solución de los conflictos contractuales, ${ }^{9}$ por otras más rápidas y factibles como la conciliación en los ordenamientos jurídicos procesales internos en cada país.

A nivel internacional, se recuerda para 1967 la aprobación de las Reglas de Conciliación del Centro Internacional para la solución de Disputas relativas a inversiones, al ofrecer servicios de resolución de conflictos comerciales a inversionistas extranjeros que tuvieran conflictos con gobiernos receptores, y en 1980 por la Resolución 35/52, Reglamento de Conciliación de la Comisión de las Naciones Unidas para el Derecho Mercantil Internacional, ${ }^{10}$ reconoció valor como método de arreglo amistoso a las controversias que surgieran en el contexto de las relaciones comerciales internacionales, aceptable para países con distintos sistemas jurídicos, sociales y económicos, a fin de contribuir al desarrollo de las relaciones económicas internacionales.

8 Vid. CASTANEDO ABAY, Armando: Mediación y conflicto comercial. El ABC para el abogado y el empresario de hoy", publicado en el Libro "Arbitraje internacional y medios alternativos de solución y litigios. Retos y realidades", hace referencia sobre ello basándose en el dicho de Eric A. Schwartz al publicar el artículo Conciliación Internacional y el ICC, en el Coloquio internacional de San Francisco, California, Octubre 17 de 1994.

9 Se recuerda que las Cámaras de Comercio en sus primeros momentos fueron conformadas por gremios de comerciantes que tenían la función de resolver los conflictos contractuales en el sector privado y el empresarial.

10 La Resolución 35/52, Reglamento de Conciliación de la Comisión de las Naciones Unidas para el Derecho Mercantil Internacional fue aprobada por la Asamblea General el 4/12/1980. 
Ante los nuevos conflictos y las nuevas formas de vida de la sociedad moderna, resulta de interés señalar, el Proyecto de Florencia (1978) y el Coloquio de Pau (1982), en ambos, los procesalistas plantearon la necesidad de obtener fórmulas alternativas de justicia, mediante la conciliación entre las partes, en función de facilitar la posterior convivencia y las buenas relaciones.

$\mathrm{Su}$ expresión procesal en Cuba vio la luz en el siglo XXI con las diferentes normas reguladoras del procedimiento económico ${ }^{11}$ hasta asumirse como institución en el Derecho Procesal Cubano, en la vigente Ley de Procedimiento Civil, Administrativo, Laboral y Económico. ${ }^{12}$ Años después, ante la experiencia y los satisfactorios resultados que de la conciliación se obtuvo en la justicia económica, el Consejo de Gobierno del Tribunal Supremo Popular cubano (CGTSP), paulatinamente fue aprobando Instrucciones destinadas a los tribunales de la jurisdicción civil, ${ }^{13}$ en las cuales se establecieron mecanismos expeditos, tendentes a dotar de mayor flexibilidad, intercambio y oportunidad entre el tribunal y las partes, mediante la actividad conciliatoria, en los asuntos de naturaleza disponible. Su máxima expresión se encuentra hoy diseñada en la Instrucción 226 del 2013, al momento de la celebración de los actos judiciales, en los asuntos civiles, de familia, administrativa y económica. ${ }^{14}$

Al definir la conciliación judicial, en la generalidad de los académicos estudiados, no existe disparidad. Esa solución

11 Gaceta Oficial Extraordinaria No.10, 16 de Agosto del 2001, Decreto Ley Número 223 del 2001, "De la jurisdicción y competencia de las Salas de lo Económico de los Tribunales Populares", pp.51-52. Artículo 1 apartado Séptimo.

12 Vid. Gaceta Oficial Extraordinaria Número33, del 27 de septiembre del 2006. del Decreto Ley No. 241 del 2006, pp.327-328.

13 Nótense las Instrucciones Números 187 de 2000, la Instrucción No. 191 de 2009 del Consejo de Gobierno del Tribunal Supremo Popular de la República de Cuba (en lo adelante CGTSP), que autorizó la aplicación por los tribunales de la jurisdicción civil de las modificaciones que en determinados aspectos de la práctica judicial introdujo, esta se derogó por la Instrucción 216 del 2013.

14 Gaceta Oficial Extraordinaria Número 45, del 30 de diciembre de 2013p. 445: Instrucción No.226: Metodología para la celebración de actos judiciales civiles, de familia, administrativa y económica. 
consensual, llamada por CAPPELLETTI como "justicia coexistencial" y por VESCOVI "justicia conciliadora", la conciben independientemente de la decisión de un tercero antes de que éste, dotado del poder de resolución, entre a hacerlo. ${ }^{15}$

MANRRESA y NAVARRO e IGNACIO MIGUEL, tratadistas españoles que comentaron la Ley de Enjuiciamiento Civil Española de 1856, la consideraron . (...) el acto legal de componer las partes ante el juez con el objeto de procurar la avenencia y transacción del pleito que la una de ellas trata de entablar contra la otra". ${ }^{16}$

Para DE LA PLAZA la conciliación es obra de la exclusiva actividad de las partes, puede no responder a las exigencias de la justicia pura, pero sí reducir los gastos y dilaciones de un proceso; tiende a evitar la litis, de ahí que como medio de composición, unas veces (en vía preventiva) impide que se promueva, y otras pone fin al pleito ya iniciado y extingue, por tal manera el proceso. ${ }^{17}$

En GOZAÍNI es la pacificación provocada por el activismo judicial en base a la audiencia y es un mecanismo dirigido a atenuar ánimos exacerbados, evitando la prolongación de un pleito que tiene respuestas anticipadas sin necesidad de obtenerlas de la sentencia definitiva. ${ }^{18}$ De igual modo, en HOET- LINARES, la conciliación es un intento de llegar a un entendimiento entre las partes que tienen un litigio, que signifique un acuerdo razonable y que excluya el conflicto y los contrayentes realicen recíprocas

\footnotetext{
15 Comentarios al respecto lo pueden consultar en: GELSI BIDART, Adolfo, TORELLO, Luís y VESCOVI, Enrique: Exposición de motivos del Anteproyecto de Código Procesal Civil Modelo para Íbero América. Revista Uruguaya de Derecho Procesal 1982, p. 161.

16 MARRESA y NAVARRO, José María y IGNACIO MIGUEL, D.: Ley de Enjuiciamiento Civil Española del 13 de Mayo de 1856 Comentada y explicada ", Revista de la Legislación y Jurisprudencia, Madrid, 1856, t.1, p.540.COUTURE, Eduardo J.: Estudios de Derecho Procesal Civil", Ed. Depairna, Buenos Aires, 1979, t.1, p.229.GUASP, Jaime: " Derecho Procesal Civil", Ed. Instituto de Estudios Políticos, Madrid, 1956, p.1234.

17 DE LA PLAZA, Manuel: " Derecho Procesal Civil español", 3era. Ed. Revista de Derecho Privado. Madrid 1951, Vol. I, p. 38.

18 GOZAíNI, Osvaldo Alfredo: Notas y Estudios sobre el proceso civil, Ed. Instituto de Investigaciones Jurídicas, Méjico, 1994, p. 50.
} 
concesiones; ${ }^{19}$ y similares definiciones, los recoge el Diccionario de Derecho Privado. ${ }^{20}$

MONTERO cree que la conciliación debe colocarse en la zona extrema, con el fin del campo jurisdiccional. CARNELUTTI, en cambio, la sitúa en la confluencia de los dos tipos de resolución de litigios, la contractual y la propiamente judicial, ya que se acomoda a la forma de mediación dirigida a obtener una composición contractual y tiene a la vez, la sustancia de las decisiones judiciales en cuanto tiende a la resolución justa y equitativa de los litigios; y en MAYNORD el fundamento de la conciliación radica en el deseo de disminuir el litigio. El proceso dice, es muy mal, y vale más un mal arreglo, que un buen pleito. ${ }^{21}$

Las uruguayas CORTI ACOSTA y FACELLI NÚÑEZ, resumen la conciliación judicial, como una etapa importante en el proceso judicial ya que, con rango constitucional, se establece su obligatoriedad previa al juicio y luego reafirma su importancia en la esfera procesal donde el legislador ha previsto además una conciliación intra-procesal al ser una de las etapas que todos los jueces han de cumplir en la audiencia preliminar, aún antes de establecer el objeto del juicio. ${ }^{22}$

19 HOET- LINARES, Franklin: La Mediación. Administración y Negociación de Justicia Alterna, 2da. Ed. LEGIS, Colombia, 2007, p.40.

20 A decir; BELLEN conceptualiza la conciliación en el acto de comparecencia de los interesados ante el juez municipal con el propósito de obtener un acuerdo amistoso, evitando la iniciación del litigio que uno proyectare o que prosiga el apresuramiento producido. CHIOVENDA la encuentra, en la intervención de una persona pública (el juez de la conciliación), pero no para decidir la controversia, sino para intentar la conciliación requerida por una parte MATTIROLO la supone necesariamente una contienda preexistente que es indispensable para el conflicto. No obstante, puede ocurrir que las partes se presenten ante el juez conciliador no para dirimir la contienda, estipular un convenio cuya eficacia quiere reconocer. En BONCENNE es solo una entrevista que la ley concede a las partes, con el fin de que puedan explicar sus respectivas pretensiones y terminar en un acuerdo. Vid. Diccionario de Derecho Privado, Ed. Labor, S.A., Barcelona, Madrid, 1950.p. 165.

21 bídem.

22 Vid. CORTI ACOSTA, Graciela y FACELLI NÚÑEZ, María T.: La experiencia uruguaya en materia de mediación y conciliación.: http://www.servilex.com.pe/arbitraje/vitrina. html (Consulta: 1 de abril de 2018, 8.18am). 
En Cuba, GONZÁlEZ ESCALONA y ARIAS MORENO la erigen imbricándose en el juez actuante las funciones propias de un agente conciliador frente a las partes litigantes ${ }^{23}$ y COBO ROURA al definirla, se extiende hasta los fines que posee; pues valora que el tercero interviniente puede contribuir a ponderar las circunstancias del conflicto con mayor flexibilidad, a encontrar las pautas que puedan conducir a su solución, a promover la comprensión y el respeto mutuo entre las partes, a identificar sus intereses comunes y ventajas recíprocas, a generar opciones, y -como razón última- a asegurar la equidad como valor razonable a alcanzar en la distribución de derechos y obligaciones, de cargas y beneficios. ${ }^{24}$

Es pues, la conciliación, dentro de lo judicial, la encargada de la aproximación de las partes que ante una determinada circunstancia, las relaciones tendieron a ser opuestas o generaron una situación de discordia, realizándose con la intervención activa del tribunal, el que, de conjunto con las partes, propondrá fórmulas propiciadoras de solución consensual, que permitan a los litigantes acatar los puntos de vista de una $\mathrm{u}$ otra, mediante el acuerdo de voluntades con equitativos compromisos, propiciando en el mejor de los casos el fin al litigio.

Al analizar la naturaleza jurídica de la conciliación judicial, se comprueba que COUTURE tiene el dilema de si es un acto del procesal, o se trata de un avenimiento entre partes donde puede haber renuncias bilaterales, en su caso, transacción propiamente dicha $;{ }^{25}$ para GUASP, es un proceso tanto de cognición especial por razones jurídico procesales, al tener como fin eliminar el nacimiento de un proceso principal ulterior, como de conocimiento, constituyendo un proceso particular al existir un reclamo

23 Vid. GONZÁLEZ ESCALONA, Yeisys y ARIAS MORENO, Aylín Belén: "Una mirada al Arbitraje Interno en los organismos de la provincia Holguín. El acceso a la Justicia": (CD ROM) Memorias del VI Encuentro Internacional Justicia y Derecho, 2012,p.4.

24 Vid. COBO ROURA, N., op.cit, p.122.

25 Vid. COUTURE, Eduardo J.: Estudios de Derecho Procesal Civil", Ed. Depalma, Buenos. Aires,1979, t.1,p.229. 
jurisdiccional que provoca una auténtica intervención judicial que intenta la avenencia o el arreglo pacífico entre las partes. ${ }^{26}$

MONTERO AROCA, ORTELLS RAMOS y GÓMEZ COLOMER, opinan que la conciliación no es un proceso, sino un acto solícito, disponible para las partes.

GONZANÍNI, ${ }^{27}$ ALONSO GARCÍA, ${ }^{28}$ CAMA GODOY, ${ }^{29}$ ÁLVAREZ DESANTI, ONFRAY, ORMAECHEA y LUZ CLARA; ${ }^{30}$ concuerdan en que la conciliación las partes ceden cierto control a un tercero neutral que guía, participa, contrasta, delimita y equilibra los intereses contrapuestos con el objetivo de avenirlos hasta solucionar pacíficamente el problema a través de un acuerdo que elimine la posible contienda judicial.

En su caso, PIERO CALAMANDREI al ubicarla por razón del órgano donde se ejercita, tanto en los organismos públicos -que resuelven controversias entre particulares típico de administración pública del derecho privado que, sin reparo alguno, puede confiarse a órganos no judiciales como cuando la conciliación se encomienda a órganos judiciales-, como en órganos judiciales formando parte de la jurisdicción voluntaria. ${ }^{31}$

Estos criterios, circunscriben la naturaleza jurídica de la conciliación judicial en dependencia del momento de su convocatoria o desarrollo; voto a favor de extender el análisis

26 GUASP, Jaime: " Derecho Procesal Civil", Ed. Instituto de Estudios Políticos, Madrid, 1956, p. 1234.

27 Vid. GOZANÍNI, Osvaldo Alfredo: "Notas y estudios sobre el proceso civil", Ed. Universidad Nacional Autónoma, Méjico, 1994, pp. 43-63.

28 Vid. ALONSO GARCÍA, Manuel:.monografías.com/mediakit. 2000. (Consultado: 17 de marzo de 2018).

29 Vid. CAMA GODOY, Henry: La Conciliación como Mecanismo Alternativo de Resolución de Conflictos.: monografías.com/mediakit. 1997. (Consultado: 28 de septiembre de 2018, Hora: 3:00 pm).

30 Vid. ÁLVAREZ DESANTI, Arnoldo; ONFRAY, Fernando; ORMAECHEA, Iván y LUZ CLARA, Bibiana Consultado en: monografías. com/mediakit. 1997. (Consulta: 17 de octubre de 2018 Hora: 3:32 pm).

31 PIERO, Calamandrei: "Instituciones de Derecho procesal civil", 2da. Ed. Italiana. Jurídicas Europa América, Argentina, 1962, Volumen I, p.198. 
teniendo en cuenta el grado de intervención del tribunal y el lugar donde se efectúe:

- De realizarse antes o durante el transcurso del proceso, fuera de la sede judicial; es un método no adversarial de conflictos.

- Luego de la interposición, y ser el litigio de conocimiento y solución conciliada del tribunal, en sede judicial, se convierte en una actividad posible de desarrollar en cualquier estado procesal, pues independientemente de que contribuye a impulsar determinada situación procesal, hasta alcanzar los acuerdos que resultaren pertinentes; puede prescindirse de su aplicación si no se promueve.

Por tanto, la naturaleza de la conciliación durante el proceso judicial, ${ }^{32}$ hace que la conciliación se despliegue: como método no adversarial, como actividad procesal y como medio extraordinario de conclusión del litigio, distinción que de ella hace el Código Procesal Civil Modelo para Ibero América aprobado en 1988.

Como método no adversarial de solución de conflictos; ya anteriormente abordado, se suscita durante el transcurso del proceso por avenencia y decisión auto compositva de las partes; también le es característico, el requisito de procedebilidad de la actividad conciliadora del tribunal anterior a la presentación de la demanda, pero se realiza en sede judicial y con la anuencia del tribunal; con la diferencia de que el juzgador en esa etapa es un desconocedor de lo que se demanda; su desempeño es avenir a las partes antes de la interposición de la litis.

32 Al no pretender dar un nuevo concepto del proceso judicial, compartimos la idea que de él hacen MORELLO y QUEVEDO, como:"Una serie sucesiva, gradual, concatenada de actos jurídicos realizados conforme al orden trazado por la ley, que han de cumplir el tribunal, las partes y terceros, en ejercicio de los poderes, derechos, facultades y cargos que les atribuye la ley procesal o en cumplimiento de los deberes y obligaciones que la misma les impone, tiene por objeto la actuación de la ley con relación a los hechos alegados y resultan probados, con el fin último de garantizar el mantenimiento del orden jurídico." Vid. MORELLO, Augusto M. y QUEVEDO MENDOZA, Efraín: Proceso y Procedimiento, ciencia y técnica (Replanteos y nuevas perspectivas), Ed. Universidad Nacional Autónoma de Méjico, Méjico, 1994, p.205. 
Francia, en el año 1995 aprobó la Ley de Conciliación y Mediación Procesal, modificativa del artículo 131 del Código de Procedimiento Civil, regula la conciliación como proceso previo y obligatorio antes de iniciar el juicio, conserva la Corte la responsabilidad y el control con respecto a la controversia, sin transferir el poder de toma de decisiones al tercero, por lo que cualquier resultado se determina al tener en cuenta la voluntad y los intereses comerciales respectivos. ${ }^{33}$

Por el Código General del Proceso de la República Oriental del Uruguay de 1988, es requisito de preceptividad la conciliación previa con el futuro demandado debiéndose pedir antes de iniciar cualquier proceso y es presidida por el tribunal; en igual sentido, lo regula el Código de Procedimiento Boliviano.

Esta forma de manifestación se constituye como requisito de procedibilidad de la actividad conciliadora del tribunal anterior a la presentación de la demanda, pero se realiza en sede judicial y con la anuencia del tribunal; con la diferencia de que el juzgador en esa etapa es un desconocedor de lo que se demanda; su desempeño es avenir a las partes antes de la interposición de la litis.

Como actividad procesal, generalmente se realiza en cualquier estado del proceso, con especial énfasis en la audiencia preliminar. El magistrado GUIOTE ORDÓÑEZ concibe la audiencia preliminar ${ }^{34}$ como la etapa procesal en la que habrán de depurarse todos los defectos y óbices impeditivos de una sentencia sobre el fondo del asunto, así como la preparación del juicio y la cobertura hacia una posible conciliación entre las partes. ${ }^{35}$

33 Vid.Regulación jurídica de la conciliación en los Códigos de procedimiento Comercialy/ oCivil.http://www.infolcg.mecon.gov/busquedas/normas.tipo=Leyes.state.md.us/district/ forms//dccrO2brsp.html. Consulta: 4 de mayo del 2018. Hora: 8:00am.

34 La Audiencia Preliminar y/o Previa surge en los albores del siglo XIX, consolidándose a mediados del mismo en la normativa procesal de los continentes europeo y americano. La palabra audiencia proviene del latín " audientía", acto de oír las personas de alta jerarquía u otras autoridades, previa concesión, a quienes exponen razones o pruebas que se ofrece a un interesado en juicio o expediente.

35 Vid. GUIOTE ORDÓÑEZ, José Antonio: "Los procesos ordinarios en el proyecto de Ley de Enjuiciamiento Civil en España", Ed. IBERIUS, España, 2004, p. 7. 
Para ROLANDO ARAZI, la audiencia preliminar constituye la base de todo el sistema; pues además de volver a intentarse una conciliación, el juez deberá dictar todas las medidas necesarias para sanear el proceso y solucionar las cuestiones que impidan la decisión de mérito; también se fijará definitivamente el objeto del proceso y de la prueba, rechazando las que fuesen inadmisibles, innecesarias o inconducentes. ${ }^{36}$

En la práctica judicial cubana, la Instrucción 226 del 2013 del CGTSP es concordante dicha percepción teórica; al amparo de las posibilidades que ofrecen la comparecencia encomendada en el artículo 42 y la audiencia preliminar, del artículo 771 de la Ley de Procedimiento Civil, Administrativo, Laboral y Económico, en ambos se diseñan las finalidades de la convocatoria del acto judicial ${ }^{37}$ encontrándose dentro ellas, la conciliación.

En vistas de ello, la Instrucción insta a que en caso de que la finalidad del acto sea la de conciliar, el tribunal fomentará el diálogo constructivo, no adversarial; escuchará a las partes, cuidará de crear un ambiente de confianza y seguridad, de manera que, a partir de la comunicación, se propicie el acercamiento de las posiciones, en principio opuestas y, cuando sea procedente dada la naturaleza del asunto, tratará de encaminar el debate hacia una solución que merezca la aceptación común de estas o que ofrezca el mayor beneficio a los intereses objeto de protección judicial, hasta la conveniencia de alcanzar un arreglo entre las partes. ${ }^{38}$

Como un medio extraordinario de conclusión del proceso la conciliación judicial es reconocida en la doctrina por DE LA PLAZA y CASTAÑEDA SERRANO; ${ }^{39}$ el acuerdo obtenido dará

36 Vid. ARAZI, Rolando: Las Ciencias Jurídicas y las nuevas tecnologías", Instituto de Informática Jurídica, Universidad del Salvador http://www.salvador.edu.ar/arazi.htm: (Consulta: 26 de abril del 2018, Hora:9:50am).

37 A los efectos de la Metodología, se entiende por acto judicial aquellos que el tribunal realiza de forma oral.

38 Ibid: Gaceta Oficial Extraordinaria Número 45, del 30 de diciembre de 2013p. 448.

39 Víd. DE LA PLAZA, Manuel: Derecho Procesal Civil español, Revista de Derecho Privado, 3era. Ed, Vol 1,Madrid, 1951,pp. 38-84.CASTAÑEDA SERRANO, Cesar: La Conciliación como 
por sentado el fin del litigio, dejará sin efecto cualquier sentencia dictada que no se encuentre firme. El Código Procesal Modelo para Ibero América, lo propugna y el Código Procesal Civil de Perú por Ley No. 26635 de 1996, es el único país de los estudiados, que de forma particular la regula como forma especial de culminación del litigio.

Así debería ser reconocida y tratada en la dogmática patria y dispositivamente, al tener los mismos requisitos y efectos jurídicos que otras formas procesales extintivas contenidas en la Ley de Procedimiento Civil, Administrativo, Laboral y Económico ${ }^{40}$, pudiendo ser resuelta con un pronunciamiento dispositivo de su incorporación dentro la reforma procesal que se avecina en la Ley de Procedimiento Civil, Administrativo, Laboral y Económico.

\section{Por la coexistencia de la conciliación fuera y dentro de sede judicial. Ventajas, riesgos y solución al dilema}

Lo anteriormente valorado, conlleva para proponer y dilucidar los siguientes cuestionamientos:

forma especial de conclusión del proceso, Revista del Poder Judicial Número 60, Ed. Escuela Judicial de España, 2000. Monografías.com/mediakit. 2000. Consulta: 3 de octubre de 2010.

40 Como medios extraordinarios de conclusión del proceso, el legislador cubano en la Ley de Procedimiento Civil, Administrativo, Laboral y Económico, además de la sentencia firme, reconoce al desistimiento y la transacción aprobada judicialmente. P ara el desistimiento el artículo 651 inciso 1) de la Ley No. 7 del 19 de Agosto del 1977 regula como requisitos, que conste por escrito la declaración formulada por el demandante de no querer continuar el ejercicio de la acción, se le dé traslado a las demás partes por el término de cinco días a fin de que muestren su conformidad o no con él, y el Tribunal resolverá lo que corresponda sobre la continuación o no del proceso. Por sí solo producirá todos los efectos si se formula antes de la contestación de la demanda o de haber transcurrido el término para contestarla, sin que se hubiere efectuado. Como formalidades de la transacción judicial, la Ley de Procedimiento específica que: Si comprende todas las cuestiones debatidas, pondrá fin al proceso, si sale algunas, éste continuará hasta que se decidan ejecutoriamente las restantes. Se presentará por escrito solicitando su aprobación. Debe estar suscrita y presentada personalmente por todas las partes o por representante con poder especial para ese acto. El Tribunal dictará auto aprobando la transacción en los términos acordados y equivaldrá a la sentencia firme. Vid: Ley No. 7 del 19 de Agosto del 1977. Art. 651 inciso 2., 652 p. 241, 242, Colección Jurídica. Ministerio de Justicia, La Habana, 1999. 
¿Qué sucede cuando la conciliación se genera fuera de sede judicial o, cuándo se efectúa en sede judicial?

\section{Primer supuesto en torno a la interrogante}

Nacido el litigio y en cualquier estado del proceso antes de que concluya, las partes fuera de sede judicial, realizan acciones recíprocas, organizadas y razonadas, que en conducen a la solución conciliada del problema, y en el mejor de los casos, llegan al acuerdo por medio del accionar voluntario, libre, privado. ${ }^{41}$

\section{Segundo supuesto en torno a la interrogante}

En sede judicial, la conciliación se genera, bajo la tutela de la autoridad judicial, de oficio o a instancia de parte, según se regule; tiene lugar durante la tramitación de la litis, con la participación pro activa del tribunal y las partes; con el objetivo de avenir las pretensiones discordantes en la controversia.

En el primer supuesto estamos en presencia de la autocomposición de la voluntad de las partes; la conciliación se manifiesta como método no adversarial de solución de conflictos. Pero advierte COBO ROURA que como forma auto compositiva, no puede ser un espejismo de la justicia $;{ }^{42}$ lo cual se aprueba, porque cuando la conciliación se produce por la voluntad auto compositiva de las partes, el tribunal se limita a velar su licitud; por demás, nada obsta que esté prevista en ley, ni se acometa su desempeño, ni se estimule a las partes a componer el litigio por ellas; de ser así se convierte en un sueño irrealizable para la justicia.

En el segundo supuesto, el motivo de que el acuerdo se realice por consentimiento y voluntad colegiada del tribunal y las partes, hace estar en presencia de la hetero composición

41 Vid. MAYO DE ÍNGARAMO, Celia A.: Los medios alternativos de solución de conflictos en el proceso civil", (CD ROM): Memorias del V Encuentro Internacional Justica y Derecho, Tribunal Supremo Popular, La Habana, 2010, p. 2215.

42 Vid. COBO ROURA, N., op.cit, p.124. 
adjudicativa de la litis, el órgano judicial conoce los pormenores del acuerdo, decide junto con las partes el mismo, revelándose la conciliación, como un acto jurídico, con carácter intra procesal, de ahí que la autora tenga a bien llamarla conciliación judicial.

Es a partir de ese momento, donde interviene el tribunal; es ahí donde convergen la auto composición de la voluntad de las partes con la hetero composición adjudicativa de la litis; ambas contarán con la aprobación del tribunal; el cual velará que el acuerdo de conciliación esté conforme a la ley; todo lo cual determina la coexistencia de la conciliación fuera o en sede judicial.

Sin embargo, no podemos estar ajenos a las ventajas y riesgos que asume el tribunal cuando efectúa la conciliación dentro o fuera de sede judicial.

Entre las ventajas de la conciliación sede judicial; el uruguayo URIARTE AUDI, al defenderla explica, que al ser de carácter intra procesal, el conflicto está mucho más acotado y cada litigante sabe cuáles son las pruebas que se diligenciarán, con lo cual puede hacer una estimación más precisa del eventual resultado. Por otro lado, el juez ya tomó conocimiento del litigio, estudió el expediente y puede proponer formulas conciliatorias. Y el hecho que el magistrado sea quien resolverá el conflicto, en caso de no lograrse acuerdo, hace que las partes presten mayor atención a sus propuestas. ${ }^{43}$

En Cuba la jueza PÉREZ RICARDO, considera que la presencia permanentemente de un juez, el cual toma conocimiento de la causa para poder aclarar el conflicto en que se basa la demanda y la contestación, buscará analizar los puntos controvertidos, para poder arribar a una fórmula conciliatoria que resulte equitativa para ambas partes. ${ }^{44}$

43 Vid. URIARTE AUDI, Gonzalo: La experiencia de 20 años de aplicación en el Uruguay. http://www.servilex.com.pe/arbitraje/vitrina. html: Consultado: 1 de abril de 2011, 4:55 pm).

44 Vid. PÉREZ RICARDO, Yunaisi: " La conciliación en el proceso civil. Necesidad de su instrumentación, " Tesis en opción al grado científico de Especialista en Derecho Civil (2008). 
A dichas consideraciones, se suman como ventajas:

\section{Para el tribunal actuante}

1. Un mejor conocimiento y contacto directo con las partes;

2. Generar transparencia en su actuar;

3. Formar convicción; a medida que se produzca y desarrolle el debate;

4. Percibir en el rostro de los contendientes, gestos reacciones, comportamientos;

5. Facilitar, simplificar, disminuir o extinguir el litigio;

6. Controlar y conducir más eficazmente el proceso en la forma que estime más conveniente, con las circunstancias del litigio y los deseos de las partes;

7. Reprimir y ordenar al instante las irregularidades que se produzcan;

8. Precisar cualquiera de las prácticas de pruebas solicitadas;

9. Recibir información de hechos, que hasta el momento no habían sido declarados;

10. Individualizar las diferencias;

11. Colaborar en las propuestas de acuerdos, con equitativos intereses para las partes;

12. Ayudar a las partes a mantener o restablecer las relaciones comerciales;

13. Reducir el tiempo de tramitación de la litis;

14. De no alcanzarse el acuerdo, concretar el objeto de la litis y lo que contraponen;

\section{Para las partes}

1. Conocer los criterios del tribunal, que tiene a su cargo el asunto litigioso;

2. Expresar libremente sus argumentaciones a favor o en contra, con las propuestas de acuerdos; 
3. Contribuir a equilibrar los derechos y deberes del tribunal;

4. Aceptar las soluciones, a las cuales llegan con la cooperación del tribunal;

5. Resultar menos costoso y demorado la solución de la litis;

6. Recuperar las relaciones existentes y la permanencia de futuras;

7. Ceder a la ejecución voluntaria del acuerdo.

Son también objeto de preocupación los riesgos que ocasiona la conciliación judicial. En su caso, en sede judicial se manifiesta ante:

\section{- La conexión directa tribunal- partes}

El siguiente ejemplo hipotético servirá de referencia para el análisis:

En la dinámica de la conciliación judicial, el juez analiza con las partes las posibles alternativas de acuerdo, en relación al pago de una deuda. La empresa demandante A está a favor de que le paguen la deuda en dos plazos y explica las causas por las cuales necesita que se haga en dicho término; mientras la empresa demandada $\mathrm{B}$ reconoce la deuda, pero persiste en que la situación de su entidad es más caótica, y por eso interesa efectuar el pago en cinco plazos. En su caso el juez, al percibir la situación económica que presentan ambas, les propone que el pago se efectúe en tres plazos.

Como resultado de ello puede suceder que: no haya acuerdo o éste es parcial. En ambos casos, se está ante el conocimiento pleno del juzgador sobre la litis, él participó en las etapas de la tramitación o en todos los actos procesales; sabe cómo va a juzgar. De igual forma, hace que el tribunal actuante sea objeto de examen; porque las partes en el desarrollo de la conciliación judicial percibieron la conducta y posición que éste asumió.

Hecho como este pudo ser el motivo de preocupación de LATORRE BOZA al no entender, cómo hará el juez para ser conciliador en un momento determinado, y despojarse de su 
investidura de magistrado, cuando inclusive, como conciliador, tendrá que sujetarse a la responsabilidad disciplinaria. ${ }^{45}$

Esta inquietud a CARNELUTTI le pareció oportuno resolverlo a través de órganos para- judiciales con cometidos afines al judicial o conexos con él, a los que están adscritos órganos especiales. Según su punto de vista, un ejemplo indudable de órgano especial para-judicial en que se piensa para realizar dicha función, es la conciliación; y reconoce que en el ordenamiento italiano el conciliador se halla, a la vez investido, aunque dentro de límites diversos, tanto con la función conciliadora como la jurisdiccional, de ahí que aparezca más bien un injerto de la función para judicial sobre el órgano judicial, que hay que tener en cuenta en una sistematización completa de los elementos del proceso, aún cuando no sea más que para diferenciarlos de los verdaderos órganos judiciales. ${ }^{46}$

Mientras, en Uruguay, no es recusable la participación del juez en el inicio del litigio, luego en la audiencia de conciliación previa, o en cualquier otro acto conciliatorio; ni las manifestaciones que realizare en éste, pueden ser causa de pre juzgamiento. Al respecto, el profesor uruguayo GONZALO URIARTE, lo celebra, para él: "(...) el juez ya tomó conocimiento del litigio, estudió el expediente y puede proponer formulas conciliatorias. Al mismo tiempo, el hecho que el magistrado sea quien resolverá el conflicto en caso de no lograrse acuerdo, hace que las partes presten mayor atención a sus propuestas. A efectos que el magistrado tenga libertad para proponer fórmulas de acuerdo, se estableció expresamente que su actividad respecto a este punto no constituye prejuzgamiento." ${ }^{47}$

\footnotetext{
45 LATORRE BOZA, Derik: La conciliación extrajudicial y el poder judicial: http://www. ambito-jurídico:br/adj/dpc0002.html. Ámbito Jurídico-DPC0002. (Consulta:1 de marzo del 2009, Hora:9:00am)

46 CARNELUTI, Francisco: Sistema de Derecho Procesal Civil, Ed. UTEHA Hispaonamericana, Argentina, 1944, p.201.

47 Vid. URIARTE AUDI, Gonzalo: "Audiencia preliminar: la experiencia de 20 años de aplicación en el Uruguay" http://www.servilex.com.pe/arbitraje/vitrina. Htm/ (Consulta: 1 de abril de 2018, Hora:5:05pm).
} 
GELSI BIDART,TORELLO y VESCOVI, también comparten la idea, al defender que el juez, como técnico en Derecho, es el mejor conciliador, es el mejor conocedor del alcance de las pretensiones; no obstante, reconocen la necesidad de dotarlo de alguna de las técnicas que le permita procurar la franca y leal colaboración, con vistas a la solución al conflicto. ${ }^{48}$

\section{- Desconocimiento del tribunal de la litis que tiene ante sus manos}

El riesgo se da cuando la conciliación judicial se efectúa por un tribunal que no participó en la mayoría de las actuaciones, no realizó la audiencia preliminar, no practicó las pruebas, o no hizo la comparecencia; en resumen, el juzgador no está en condiciones de percibir los puntos de contactos y diferendos que durante la sustanciación del asunto pudieron en un momento dado haber obtenido las partes, por demás se presenta ante él la complejidad del asunto y de las partes.

En los justiciables, puede estar el temor respecto a la conducta que seguirá el tribunal, la conciliación que convoque y el resultado del litigio; lo que pudiera ocasionar que expresen su parecer con reservas.

Este riesgo no es impedimento en el Código Procesal Civil y Mercantil de Guatemala y el Código Procesal Civil y Comercial de Argentina, mas el Código General del Proceso del Uruguay y el Código Procesal Civil de Perú, tienen la particularidad de que en cualquier estado de la litis el juez procederá a la conciliación judicial a instancia de parte, y en el Código de Procedimiento Civil de Bolivia, es a instancia del actor.

Fuera de sede judicial los riesgos procesales se producen, debido a:

48 GELSI BIDART, Adolfo; ORELLO, Luís y VESCOVI, Enrique: Anteproyecto de Código Procesal Civil Modelo para Iberoamérica. Exposición de Motivos. http://www.ambito-jurídico:br/adj/ dpc0002.html. Ámbito Jurídico-DPC0002. Consultado en el Centro de Información Científica del Tribunal Supremo Popular de Cuba, el 26 de Abril del 2010. 


\section{- La inercia o pereza y la rapidez}

Al estudiar el Sistema de Derecho Procesal Civil, Carnelutti lo identifica como el estímulo y, recíprocamente el freno para la acción a cargo de las partes, de manera que las mismas al realizar la conciliación fuera de sede judicial, o se sienten estimuladas a actuar oportunamente y con cautela, creándose así un sistema de estímulos y de contra estímulos aptos para solicitar y para rectificar su acción; es decir, una parte la excita a actuar enseguida, con rapidez ; mientras la otra lo retiene, espera. ${ }^{49}$

Ejemplo de lo anterior lo preciamos en el proceso ordinario número 550 del 2012 de la sala de lo económico del Tribunal Provincial Popular de La Habana, en la audiencia preliminar ambas partes estuvieron conformes en realizar la conciliación fuera de sede judicial, vencido el término concedido por los jueces actuantes, no lo cumplieron, ante esto, la Sala convocó a comparecencia y en ella las partes presentaron escrito con los acuerdos arribados. ${ }^{50}$

Otro ejemplo ilustrativo, pero de pereza. Al realizar la conciliación con rapidez, hace que las partes en ocasiones lleguen a acuerdo parcial, o no lleguen a acuerdo alguno, influye en eso que se aferren a sus posiciones, o al ver que la propuesta no se adecua a la pretensión de la contraparte, deciden no llegar a acuerdo para que sea el tribunal el que determine el litigio mediante decisión condenatoria.

\section{- Menos posibilidad del juez en ser parcial}

Al mismo tiempo puede constituir un riesgo y una ventaja. Para el tribunal, es una ventaja porque, al no participar en la conciliación, motiva la no predisposición con o una de las

\footnotetext{
49 CARNELUTI, Francisco: Sistema de Derecho Procesal Civil, 2da parte, Ed. UTEHA Hispanoamericana, Argentina, 1944, p. 80.

50 Vid. Auto número 384 del 19 de septiembre del 2012,Expediente número 550 del 2012 de la sala de lo económico del Tribunal Provincial Popular de La Habana
} 
partes (como anteriormente se analizó ante la conexión directa tribunal-partes). Para las partes permite que no se sientan coaccionados ante la presencia del juzgador el cual advertirá y requerirá la conducta, actuación y el parecer al momento de determinar sus intereses y pretensiones.

Quizás, esta sea la posición asumida en algunos ordenamientos jurídicos como Francia, el Código de Procedimiento Civil, de sumisión del Tribunal de Comercio, donde autoriza al juez a designar a un tercero denominado "conciliador de justicia" diferente al que conoce el caso para que realice esfuerzos de arreglo de los intereses de las partes al margen del tribunal, lo que no obsta que las partes puedan acordar que la efectúe el propio tribunal que lo viene conociendo.

La misma tendencia tiene el Código de Procedimiento de Colombia, al contar con un Centro de Conciliación adscrito al Tribunal de Justicia para que las partes puedan resolver las diferencias surgidas entre ellas.

A la altura de la investigación, no se puede cerrar el análisis, sin encontrar una salida que logre equilibrar, tanto para el tribunal como para las partes, las ventajas y los riesgos de la conciliación judicial dentro o fuera de sede judicial. La experiencia acumulada de su ejercicio en la práctica judicial, hace encontrar la solución, en la acertada aplicación de los principios generales de derecho; al constituir fundamentos universales, que sirven de guías a cualquier rama jurídica para solucionar problemas cuando la ley calla o es necesario reforzarla en relación a un asunto particular. ${ }^{51}$

En el espectro del ordenamiento procesal, vale mencionar, delimitar y concatenar los principios generales de Derecho que aplicará el tribunal, a los efectos de lograr avenencia de partes mediante la conciliación, y garantizar seguridad jurídica al momento de su aplicación:

51 Vid. MARTín HERNÁNDEZ, Gerardo: Manual de Derecho Procesal Civil I, Ed. NICA, Managua, 2000, p.177.ESCOBAR FORNOS, Iván: "Introducción al proceso", 2da. Ed. HISPAMER, Managua 1998, p. 494. PALLARES, Eduardo: Derecho Procesal Civil, p. 69. 
- Autonomía de la voluntad de las partes, disposición, colaboración y flexibilidad: en el sentido de que el tribunal, advertido de la conveniencia de promover la comunicación entre las partes, constatará si están en disposición y voluntad de proceder a resolver los intereses y pretensiones contrapuestos mediante la conciliación judicial.

Las partes deberán prestarse la debida cooperación y responsabilidad, tanto en el desarrollo de la conciliación como en el cumplimiento voluntario del acuerdo y el tribunal corregirá todo acto contrario a la buena fe.

- Inmediación, contradicción e igualdad de las partes: a los efectos de que la sala de justicia, en la audiencia preliminar, la práctica de pruebas, la comparecencia o en cualquier otro estado del proceso; sea el mismo, que realice la conciliación judicial.

Al conciliar las partes tendrán las mismas oportunidades para alegar o refutar las propuestas conciliadoras que laceren sus pretensiones o den muestras de parcialidad o prejuicios. El tribunal cuidará porque prime el debido respeto y cordialidad; actuará con la debida diligencia; se abstendrá de proponer fórmulas conciliatorias favorecedoras de manera desigual a algunas de las partes y debe lograr que haya equidad en las obligaciones a las cuales las partes se comprometieron.

- Oralidad, Escritura y Confidencialidad: luego de escuchadas, analizadas las propuestas conciliatorias orales o escritas, el tribunal procederá a consignar en acta el acuerdo alcanzado y las obligaciones a las que se someterán las partes, advertidas de que sus declaraciones e informes, no podrán ser alegadas como medio probatorio en contra de la otra, ni por el tribunal.

- Imparcialidad, interés general y legalidad: para que el tribunal no comprometa su probidad, lo que mantendrá de continuar el litigio, por no haberse logrado acuerdo alguno o ser éste parcial. Para que sea garante de que el acuerdo 
conciliatorio no esté contrario a Ley, no vaya contra del plan, el presupuesto y las finalidades del contrato económico, en cumplimiento de la satisfacción de las necesidades sociales del Estado. Por demás, el acuerdo tiene que ser real, límpido y viable de cumplimiento voluntario.

- Concentración, preclusión, economía procesal y celeridad: el tribunal precisará con las partes el objeto por el cual se convoca la conciliación, vigilará que se realice dentro del plazo dispuesto y sin interrupciones que faciliten dispersión, dilación y continuas e innecesarias notificaciones a las partes.

De no lograr el acuerdo o ser este parcial, se concretarán los aspectos controvertidos, los acordados y los latentes, y de oficio; procederá a la convocatoria del acto procesal correspondiente. Nada impide que se abrevien los plazos, se suspenda o continúe con posterioridad la conciliación, cuando lo amerite, por razón de la complejidad del litigio, de las partes y de las pretensiones.

Apelar a los principios generales de derecho y aplicarlos en la conciliación judicial fuera o dentro de sede judicial en su justa medida, son garantías de una impartición de justicia con eficacia, certeza y probidad.

\section{Nota final}

El estudio doctrinal y de la regulación de la conciliación judicial en el procedimiento civil, de familia, administrativo y económico cubano, más la experiencia de su ejercicio en la práctica judicial, propiciará la viabilidad de la solución del litigio de forma armónica, reducirá el temor que por lo general posee el litigio, fortalecerán las relaciones de colaboración entre las partes, contribuiría a educar a los jueces, abogados y personas jurídicas y naturales, a la cultura del diálogo, el entendimiento, en aras de garantizar el bienestar individual y colectivo.

Dejo por sentada esta hipótesis, para abrir el camino a próximas consideraciones. 


\section{Bibliografía}

\section{Autores}

AA.VV.: La Santa Biblia. Antiguo y Nuevo Testamentos, Ed. Sociedades Bíblicas Unidas, España, 1992.

ABEL LLUCH, XAVIER: "La Audiencia Previa: entre el deseo y la realidad ", Revista del Poder Judicial Número 69, Ed. Escuela Judicial, 2003.

CASTAÑEDA SERRANO, CESAR: La Conciliación como forma especial de conclusión del proceso", Revista del Poder Judicial Número 6O, Ed. Escuela Judicial de España, 2000.

COBO ROURA, Narciso: "Temas de Derecho Económico", De cara al conflicto, Ed. Félix Varela, La Habana, 2005.

CHIOVENDA, José: "Principios de Derecho Procesal Civil", Ed. REUS S.A., Madrid, 1922., t.1.

DE LA PLAZA, MANUEL: Derecho Procesal Civil Español, Vol. I, 3era.Ed.Revista de Derecho Privado, Madrid, 1951.

ESCOBAR FORNOS, IVÁN: Introducción al proceso,2da. Ed. HISPAMER, Managua, 1998.

FAIREN GUILLEN, VICTOR: El desistimiento y su bilateralidad en primera instancia, Ed. Bosch, Barcelona, 1950.

FOURNIER DUHARTE, Niurka: La función conciliadora en la audiencia preliminar, Revista Jurídica Justicia y Derecho Número 13, La Habana, 2009.

-: La función conciliadora en la audiencia preliminar", Arbitraje Internacional y medios alternativos de solución de conflictos: retos y realidades", Ed. Artes Gráficas Buschi S.A, Argentina, 2010 .

—: La conciliación judicial en el procedimiento económico cubano (2012).

LARA PEINADO Y LARA GONZÁLEZ: "Los primeros Códigos de la Humanidad", Ed. Tecnos, 2001.

MARTÍN HERNÁNDEZ, GERARDO: Manual de Derecho Procesal Civil I, Ed. NICA, Managua, 2000.

MATOS ALFARO, Juan: El proceso ante la jurisdicción de lo Económico, (CDROM) Memorias del IV Encuentro Internacional 
Justicia y Derecho, Tribunal Supremo Popular de la República de Cuba, La Habana, 2008.

MENDOZA DÍAZ, Juan: El proceso económico. Retos y perspectivas, (CDROM) Memorias del II Congreso Nacional de Derecho Procesal, 2008.

PINO MARTÍNEZ, Yolanda y HERNÁNDEZ MARTÍNEZ, Alina: Las costas procesales. Comportamiento en la jurisdicción económica, (CDROM) Memorias del IV Encuentro Internacional Justicia y Derecho, Tribunal Supremo Popular de la República de Cuba, La Habana, 2012.

MORELLO, AUGUSTO M. y QUEVEDO MENDOZA, EFRAÍN: Proceso y Procedimiento, ciencia y técnica (Replanteos y nuevas perspectivas), Ed. Universidad Nacional Autónoma de Méjico, Méjico, 1994.

PÉREZ RICARDO, Y.:"La Conciliación. Necesidad de su instrumentación" (2008).

\section{Legislaciones}

- Constitución de la República de 1976.

- Ley Número 7 de 19 de agosto de 1977, Ley de Procedimiento Civil, Administrativo, Laboral y Económico, modificada por el Decreto Ley Número 241 del 26 de septiembre del 2006.

- Código Procesal Civil Modelo para Iberoamérica fue aprobado en 1988 aprobado por el Instituto Iberoamericano de Derecho Procesal, en Montevideo en el año 1988.

- Código de Procedimiento Civil de Colombia, por Decretos Números 1400 y 2019 de (agosto 6 y Octubre 26) de 1970.

- Código de Procedimiento Civil de Ecuador, Codificación No. 000. RO/ Sup 687 de 18 de Mayo de 1987. Código de Procedimiento Civil de Chile modificaciones a este Código por Decreto N. ${ }^{\circ} 1.107$ del Ministerio de Justicia, que aprueba el texto del Código .Ley N. ${ }^{\circ} 1.552$.

- Ley de Procedimiento Civil de Perú, Ley No. 26635, publicada el 23 de junio de 1996.

- Ley de Conciliación y Mediación Procesal de Francia aprobada en el año 1995. 
- Código Procesal Civil y Mercantil, de Guatemala, 14 del septiembre de 1963. con modificaciones por Decreto 107.

- Código Procesal Civil y Comercial de la Nación de Argentina, Ley 17.454,por Decreto 1042/81 (Boletín Oficial del 27-8-81), entró a regir a partir de los 180 días después de publicada, con las modificaciones introducidas por el Decreto 1387/01 (B.O. 02-11-2001) y por reforma de Ley 25488 (B.O, 22/11/2002.)

- Código General del Proceso de Uruguay, Ley 15.98218 de octubre de 1988.

- Código de Procedimiento Civil de Bolivia, de 2 de abril de 1976.

- Código de Procedimiento Civil de Colombia, por Decretos Números 1400 y 2019 de 1970 (agosto 6 y Octubre 26).

- Ley de Enjuiciamiento Civil de España, Ley 1 del 7 de enero del 2000.

- Instrucción Número 187 de 2000 del Consejo de Gobierno del Tribunal Supremo Popular de Cuba.

- Instrucción No. 191 de 2009, del Consejo de Gobierno del Tribunal Supremo Popular de Cuba.

- Instrucción No. 217 de 2013, del Consejo de Gobierno del Tribunal Supremo Popular de Cuba.

- Instrucción 226 de 2013 del Consejo de Gobierno del Tribunal Supremo Popular de Cuba. 